\title{
El coyotaje visto desde la mirada de mujeres migrantes centroamericanas
}

\author{
Simón Pedro Izcara Palacios*
}

Perfiles Latinoamericanos

Flacso México

\section{Resumen}

Este artículo se fundamenta en una metodología cualitativa que incluyó la realización de entrevistas en profundidad a ochenta mujeres centroamericanas que contrataron polleros para llegar a Estados Unidos; el objetivo es examinar qué visión tienen del coyotaje. De los datos se desprende que los traficantes engańaron a una sexta parte de las entrevistadas y que a siete las agredieron con algún tipo de abuso sexual. Sin embargo, más de dos tercios opinaron positivamente de ellos; esto no significa que los polleros se ganen siempre su confianza; en general las mujeres solo se fían de los que les recomiendan familiares o amigos.

\begin{abstract}
This article, based on a qualitative methodology that includes in depth interviews with eighty Central American women who used migrant smugglers to reach the United States, examines her point of view about migrant smuggling. This paper concludes that one-sixth of respondents were deceived by migrant smugglers, and seven women suffered some form of sexual abuse from them, however more than two-thirds of the interviewees expressed a positive opinion towards migrant smugglers. This does not mean that women always trust migrant smugglers, they generally only trust those who were recommended for relatives or friends.
\end{abstract}

Palabras clave: coyotaje, polleros, mujeres centroamericanas, abuso sexual, delincuencia organizada, autoridades migratorias, México.

Keywords: Coyotaje, migrant smugglers, Central American women, sex abuse, organized crime, immigration authorities, Mexico.

* Doctor en Sociología por la Universidad Complutense de Madrid, y profesor de Tiempo Completo en la Unidad Académica Multidisciplinaria de Ciencias, Educación y Humanidades de la Universidad Autónoma de Tamaulipas. 


\section{Introducción ${ }^{1}$}

E

las dos últimas décadas cuatro tragedias relacionadas con el tráfico de migrantes conmocionaron la opinión pública internacional. El 6 de junio de 1993 murieron por ahogamiento en el área de Rockaway Beach, Nueva York, diez de los más de 260 migrantes chinos que saltaron del carguero hondureño Golden Venture al ser detectados por los guardacostas (Zhang \& Chin, 2007: p. 749). El 18 de junio de 2000 en Dover murieron por asfixia 58 de los 60 migrantes chinos que estaban escondidos en un contenedor de tomates (Van Liempt \& Sersli, 2013). El 14 de mayo de 2003 murieron por hipertermia en Victoria, Texas, 19 de los 74 migrantes latinoamericanos que iban escondidos en la caja de un camión refrigerador (Ramos, 2006). Asimismo, el 3 de octubre de 2013 más de tres centenares de migrantes procedentes principalmente de Eritrea y Somalia murieron ahogados frente a las costas de Lampedusa, en el extremo más meridional de Italia, cuando se incendió la embarcación donde viajaban. Estos sucesos han hecho que la opinión pública equipare el tráfico de migrantes con el de esclavos, y han justificado una mayor persecución de esta actividad y un incremento de las penas contra las personas que lucran con este negocio, que ha sido asociado con el crimen organizado.

Las mujeres son más vulnerables que los hombres a los abusos por parte de los traficantes de migrantes. Durante el tránsito irregular desde el país de origen al de destino muchas mujeres sufren violaciones (Terrón-Caro \& Cueva, 2014: p. 234; Andrade Rubio, 2016: p. 27), mientras que otras son abandonadas en terrenos inhóspitos porque no pueden seguir el ritmo impuesto por los hombres que viajan con ellas (O’Leary, 2009: p. 28; Terrón et al., 2014: p. 146).

Sustentado en una metodología cualitativa, este artículo tiene por objetivo examinar qué visión del coyotaje ${ }^{2}$ tienen las mujeres indocumentadas centroamericanas que se encuentran en tránsito por México para llegar a Estados

1 Expreso mi agradecimiento al fomix (Fondo Mixto de Fomento a la Investigación Científica y Tecnológica, Conacyt-Gobierno del Estado de Tamaulipas) por el apoyo recibido a través del proyecto tamps2011-C35-183151 "Impacto social de la transmigración y deportación de indocumentados hacia Tamaulipas".

2 Los términos coyote, pollero y traficante de migrantes son utilizados como sinónimos en este artículo. Criterio que también se aplica a coyotaje y tráfico de migrantes. Por su parte, los términos "traficante de migrantes" y "tráfico de migrantes" son muy peyorativos, debido a que pueden confundirse con los ingleses "human trafficker" y "human trafficking". Dos designaciones menos despectivas son "contrabandista de migrantes" y "contrabando de migrantes", traducciones literales de "migrant smuggler" y "migrant smuggling". Sin embargo, en este texto he preferido utilizar el primer par de conceptos porque los términos "contrabandista de migrantes" y "contrabando de migrantes" son extraños en el idioma español. 
Unidos. En primer lugar, se examina la metodología utilizada y se describe la muestra; luego se analiza la escisión del discurso académico en torno al coyotaje; más adelante se estudian las causas de la desconfianza que las mujeres centroamericanas tienen de los traficantes; después se exponen los problemas de abuso sexual sufrido por las mujeres, y finalmente se describe cómo los traficantes de migrantes engañan a las mujeres centroamericanas.

\section{Metodología y descripción de la muestra}

Esta investigación se fundamenta en una metodología cualitativa, mientras que la entrevista en profundidad fue la técnica utilizada para el acopio de información. Las entrevistas — con duración superior a una hora- fueron grabadas y trascritas literalmente.

Para seleccionar a las entrevistadas se utilizó el muestreo en cadena, en un trabajo de campo realizado en Tamaulipas, la Ciudad de México, Chiapas, Veracruz, San Luis Potosí y Nuevo León. Así, entre mayo de 2011 y junio de 2014 fueron entrevistadas ochenta mujeres centroamericanas que habían contratado en una o más ocasiones los servicios de polleros. Setenta y cinco habían emigrado en una o más ocasiones a Estados Unidos y habían sido deportadas, y cinco intentaban emigrar por primera vez a dicho país.

Originarias de Guatemala, El Salvador, Honduras, Nicaragua, Belice y Colombia, las entrevistadas residían de modo temporal en Veracruz, Tamaulipas, la Ciudad de México, Chiapas, San Luis Potosí y Nuevo León (tablas 1 y 2).

Tabla 1. País de procedencia de las mujeres entrevistadas

\begin{tabular}{cccccccc}
\hline & Guatemala & El Salvador & Honduras & Nicaragua & Belice & Colombia & Total \\
\hline$n$ & 54 & 15 & 7 & 2 & 1 & 1 & 80 \\
$\%$ & 67.50 & 18.75 & 8.75 & 2.50 & 1.25 & 1.25 & 100 \\
\hline
\end{tabular}

Fuente: Elaboración propia.

Tabla 2. Lugar de residencia temporal de las mujeres entrevistadas

\begin{tabular}{lccccccc}
\hline & Veracruz & Tamaulipas & $\begin{array}{c}\text { Ciudad de } \\
\text { México }\end{array}$ & Chiapas & $\begin{array}{c}\text { San Luis } \\
\text { Potosí }\end{array}$ & Nuevo León & Total \\
\hline$n$ & 27 & 23 & 22 & 5 & 2 & 1 & 80 \\
\hline$\%$ & 33.75 & 28.75 & 27.5 & 6.25 & 2.5 & 1.25 & 100 \\
Fuente: Elaboración propia. & & & & & &
\end{tabular}

Las entrevistadas presentaron una media de edad de 27.9 años, 3.6 años de educación y habían viajado una media de dos veces guiadas por polleros (tabla 3). 
Tabla 3. Características sociodemográficas de las mujeres entrevistadas

\begin{tabular}{lcccc}
\hline & Edad & $\begin{array}{c}\text { Años de } \\
\text { educación }\end{array}$ & $\begin{array}{c}\text { Número de veces que han } \\
\text { viajado con polleros }\end{array}$ & $\begin{array}{c}\text { Número de meses con residen- } \\
\text { cia temporal en México }\end{array}$ \\
\hline Media & 27.95 & 3.65 & 2.06 & 6.83 \\
Mediana & 28 & 4 & 2 & 5 \\
Moda & 30 & 6 & 2 & 2 \\
Mínimo & 19 & 0 & 1 & 56 \\
Máximo & 41 & 9 & 4 & 7.72 \\
Desviación estándar & 4.56 & 2.62 & 0.46 &
\end{tabular}

Tabla 4. Circunstancia que motivó el varamiento de las entrevistadas en México

\begin{tabular}{|c|c|c|c|}
\hline & & $n$ & $\%$ \\
\hline \multirow{6}{*}{$\begin{array}{l}\text { Circunstancia } \\
\text { relacionada } \\
\text { con la delin- } \\
\text { cuencia }\end{array}$} & Fueron secuestradas o engañadas por delincuentes, y sufrieron explotación sexual. & 26 & 32.50 \\
\hline & $\begin{array}{l}\text { Engañadas y secuestradas por delincuentes, pero no sufrieron explotación } \\
\text { sexual. }\end{array}$ & 1 & 1.25 \\
\hline & Los delincuentes les robaron todo lo que tenían y algunas padecieron violación. & 4 & 5.00 \\
\hline & Los delincuentes les robaron lo que tenían y asesinaron al pollero. & 1 & 1.25 \\
\hline & Los delincuentes asesinaron al pollero y explotaron sexualmente a la migrante. & 1 & 1.25 \\
\hline & Total & 33 & 41.25 \\
\hline $\begin{array}{l}\text { Circunstancia } \\
\text { relacionada } \\
\text { con los } \\
\text { polleros }\end{array}$ & $\begin{array}{l}\text { El pollero las engañó, las abandonó, no las llevó hasta el lugar acordado o les } \\
\text { robó el dinero que tenían. }\end{array}$ & 13 & 16.25 \\
\hline \multirow{6}{*}{$\begin{array}{l}\text { Circunstancia } \\
\text { relacionada } \\
\text { con las auto- } \\
\text { ridades }\end{array}$} & $\begin{array}{l}\text { Las autoridades (policías y el INM) les robaron el dinero que traían o sufrieron } \\
\text { alguna clase de agresión. }\end{array}$ & 12 & 15.00 \\
\hline & La policía detuvo y vendió a la mujer migrante a la delincuencia organizada. & 1 & 1.25 \\
\hline & $\begin{array}{l}\text { Las autoridades mexicanas detuvieron al pollero y las migrantes fueron deporta- } \\
\text { das a sus países. }\end{array}$ & 6 & 7.50 \\
\hline & Las autoridades mexicanas las deportaron a sus países. & 1 & 1.25 \\
\hline & Las autoridades estadounidenses las deportaron a México. & 1 & 1.25 \\
\hline & Total & 21 & 26.25 \\
\hline \multicolumn{2}{|c|}{$\begin{array}{l}\text { Carecían de dinero para pagar la tarifa del pollero, o tenían dinero pero todavía no habían contac- } \\
\text { tado con un pollero confiable }\end{array}$} & 26 & 32.5 \\
\hline
\end{tabular}

Las entrevistadas deseaban llegar a los Estados Unidos; sin embargo, habían quedado varadas en México porque habían sufrido algún tipo de dificultad en su tránsito por este país. Por esto habían residido temporalmente en México una media de 6.8 meses, aunque en algunos casos esto se reducía a un mes y en otros el tiempo se prolongaba a 56 meses desde que habían abandonado su lugar de origen (tabla 3).

Es así que las entrevistadas no llegaron a Estados Unidos según su calendario planeado debido a circunstancias diferentes. Algunas fueron secuestradas por la delincuencia organizada y se les obligó a participar en actividades delictivas; si bien y principalmente sufrieron explotación sexual. Otras pagaron todo el 
dinero que tenían a los polleros, pero estos las engañaron y abandonaron, huyendo y estafándolas. En otros casos perdieron lo pagado a los polleros porque estos fueron asesinados por delincuentes o detenidos por las autoridades. Otras señalaban que las autoridades (las policías y el Instituto Nacional de Migración, INM) o los delincuentes les habían robado el dinero con el que viajaban. Como contraste, un tercio de las entrevistadas no fueron agredidas en ninguna forma. Su varamiento en México se debía a que no podían pagar las tarifas de los polleros, o no habían podido encontrar a uno confiable (tabla 4).

\section{La escisión del discurso académico en torno al coyotaje}

En las últimas décadas el coyotaje ha dejado de considerarse como una actividad a pequeńa escala conducida por personas unidas a los migrantes por lazos de amistad, paisanaje o consanguinidad, a ser entendido como un negocio mayor, con lazos con el crimen organizado, y conducido por personas desinteresadas por el bienestar de los migrantes. Esta imagen predomina en el discurso oficial y en los relatos periodísticos (Spener, 2011: p. 168).

El discurso académico se escinde entre una visión que presenta el tráfico de migrantes como una actividad lúgubre, asociada a la delincuencia organizada, y otra cuya mirada es más benevolente con el coyotaje. Esta escisión se explica por el diferente acercamiento metodológico a tal objeto de estudio. El primer tipo de investigaciones en general se fundamentan en fuentes secundarias (artículos periodísticos, informes oficiales o datos estadísticos sobre detenciones) o en entrevistas a migrantes que sufrieron alguna forma de abuso por parte de los coyotes. Estos estudios describen a los migrantes como víctimas indefensas y a los traficantes como personas crueles. Como contraste, los investigadores que recogen el discurso de los traficantes tienden a subrayar la agencia y autonomía de los migrantes.

La forma más adecuada de estudiar el tráfico de migrantes es de modo directo, a través del discurso de los traficantes, ya que nadie conoce mejor que ellos la actividad que realizan. Pero estas investigaciones son escasas debido a la dificultad y riesgo que comportan. Aunque los traficantes pueden ofrecer una visión excesivamente benigna de su oficio y es posible que los investigadores accedan sobre todo a los menos violentos (Zhang, 2008: p. 248). Un estudio indirecto de esta actividad mediante artículos periodísticos, fuentes oficiales o el discurso de las víctimas de abusos tampoco es imparcial. Los migrantes que llegan sanos y salvos a sus destinos no son noticia; en los medios de comunicación solo aparecen los que padecieron situaciones violentas. El instinto de preservación del statu quo provoca que el discurso oficial presente a los traficantes 
como personas despiadadas; lo que permite justificar un presupuesto cada vez más elevado para perseguir esta actividad. Finalmente, es lógico que las víctimas de abusos refieran una imagen negativa del coyotaje.

El influyente modelo teórico sobre el tráfico de migrantes que desarrollaron Salt \& Stein (1997: p. 480) calificaba a dicha actividad como un negocio global, cada vez más sofisticado, ligado al crimen organizado, y describía a los migrantes como víctimas pasivas sometidas a prácticas inhumanas. Algunos estudios empíricos han asociado el tráfico de migrantes al secuestro y al narcotráfico. Slack (2015: p. 4), en un estudio sobre el secuestro de migrantes, señala que el 51\% de los secuestrados fueron víctimas de los coyotes o guías que los conducían, y que en el $32 \%$ de las casas de seguridad donde los retuvieron había drogas. Terrón-Caro \& Cueva (2014: p. 237) también constataron que algunos polleros secuestraban a los migrantes para extorsionar a los familiares de estos últimos. Triandafyllidou \& Maroukis (2012), en un estudio de los flujos migratorios desde Asia y África hacia Europa, asocian las redes de tráfico de migrantes con actividades ilícitas como el secuestro y el tráfico de drogas. ${ }^{3}$ Otros análisis han constatado que las redes de tráfico de migrantes abandonan en el camino a los más débiles del grupo: mujeres, nińos y adultos mayores (O’Leary, 2009: p. 28; Terrón-Caro \& Cueva, 2014: p. 227).

Como contraste, Spener, autor de una extensa obra sobre el coyotaje fundamentada en entrevistas en profundidad a coyotes, presenta, según Slack \& Whiteford (2010: p. 89), "una imagen sumamente positiva [de los coyotes]". Spener (2011: p. 160) habla de una alianza entre coyotes y migrantes, y describe el coyotaje como un elemento central de la resistencia hormiga de los migrantes frente al apartheid global impuesto en la frontera mexicano-estadounidense. De este modo, coyotes y migrantes participan en una alianza estratégica para confrontar a un enemigo común: el Estado, que los persigue por igual. Spener (2009: p. 232) señala que el sufrimiento padecido por los migrantes no es perpetrado por los coyotes, sino por la violencia estructural erguida en nombre de la defensa de la soberanía nacional. Según este autor, la ideología nacionalista genera una violencia cultural que legitima el ejercicio de una violencia estructural contra los migrantes, al mismo tiempo que imputa su sufrimiento a la violencia personal cometida por los coyotes (Spener, 2011: p. 167).

Otros estudios empíricos que involucran la realización de entrevistas a traficantes de migrantes llegan a conclusiones similares. López (1997: p. 970) en una investigación pionera donde fueron entrevistados once coyotes describe el tráfico de migrantes como un negocio pacífico donde nadie sale lastimado.

3 Aunque también destacan la agencia de los migrantes y señalan que estas redes no se asemejan a organizaciones mafiosas. 
Zhang (2008), quien fundamenta sus hallazgos en un extenso trabajo de campo que incluyó la realización de 129 entrevistas con traficantes de migrantes, los describe como personas unidas a los migrantes por lazos de parentesco, amistad o paisanaje, y señala que el uso de la violencia es poco común. Este autor afirma que no siempre los traficantes ingresan a este negocio ilícito por avaricia o aspectos económicos, sino que algunas veces lo hacen por motivos altruistas (Zhang, 2008: p. 34; Zhang et al., 2007: p. 712). Asimismo, Sánchez (2015), una autora que deriva sus conclusiones de entrevistas con 66 traficantes de migrantes, señala que las mujeres, en especial, se involucran en esa actividad más por motivos sociales como ayudar a amigos y a familiares a reunirse con sus familias, que por motivos económicos.

\section{La desconfianza de las mujeres centroamericanas hacia los traficantes de migrantes}

Durante los últimos años la violencia sufrida por los migrantes centroamericanos en tránsito por México ha crecido notablemente. Robos, secuestros, asesinatos y desapariciones se han incrementado. Esto ha hecho que el miedo de los migrantes por transitar por México haya crecido. El coyotaje ha sido impactado por el esparcimiento de la violencia. Abundan los falsos polleros que engañan a los migrantes; otros que son inexpertos los abandonan. Aunque los polleros más peligrosos son aquellos que pasaron a trabajar para la delincuencia organizada, muchas veces bajo coacción, ya que una de las actividades que aquella realiza es el secuestro de migrantes (Izcara, 2015: p. 9).

Las mujeres entrevistadas mostraban cierta desconfianza hacia los polleros. Cuando ellas comparaban su experiencia de la primera vez que transitaron por México con la última, aludían de forma reiterada a un incremento del peligro. Así lo decía Norma: "antes no había violencia como la que está ahora". Las entrevistadas señalaban que el incremento de la violencia había afectado al coyotaje; que antes había más polleros buenos, mientras que ahora muchos polleros roban y secuestran a los migrantes: "Antes era diferente la gente, no había maldad como ahora; los polleros eran comprometidos con la gente que llevaban, eran responsables y buenos" (Antonia). "Antes te llevaba el pollero y había confianza, ya no es lo mismo que antes [...] Ya no hay tanta confianza, no se puede confiar en los polleros" (Teresa).

En los últimos ańos las redes de tráfico de migrantes han crecido en complejidad. Algo más de una década atrás predominaban las redes simples unicelulares, donde un solo pollero lideraba una red que transportaba a los migrantes desde un punto de México hasta los Estados Unidos. En la actualidad muchas 
de estas redes han dejado de operar (Izcara, 2014: p. 89). Muchos polleros que lideraban estas redes han dejado su independencia para integrarse a redes pluricelulares más complejas, donde son trabajadores asalariados con funciones más simples. Las redes de tráfico de migrantes se han transformado para poder operar con más eficiencia en un contexto con nuevos actores incursionando en este negocio. La presencia de la delincuencia organizada ha mermado la rentabilidad y capacidad de operación de las redes simples unicelulares (Izcara, 2012: p. 363). Para poder pagar los sobornos muchas redes se han fusionado, y el número de sus células se ha multiplicado para generar economías de escala.

Este proceso de complejización de las redes de tráfico de migrantes era desaprobado por un alto porcentaje de las entrevistadas. Muchas señalaban que su primera migración a Estados Unidos había sido guiada por un solo pollero que las acompañó durante todo el trayecto hasta el lugar de destino. Ahora pocas redes unicelulares pueden operar desde Centroamérica o desde el sur de México hasta Estados Unidos. En su último viaje, las entrevistadas descubrieron que las redes antes compuestas de una célula ahora operaban por medio de múltiples células. Cada una de estas recorre un espacio reducido del territorio mexicano; así, para llegar hasta la frontera estadounidense, los migrantes transitan a través de diferentes células. Por eso la opinión de las entrevistadas: "antes los polleros eran más responsables y no estaban divididos como ahora" (Florencia); "antes trabajaban los polleros solos, no trabajaban así entre varios; antes no era así, que el trabajo se hiciera entre varios polleros, los polleros trabajaban por sí solos con la gente que llevaran, eran mejores los polleros antes" (Gloria).

La desconfianza hacia los polleros aparecía reflejada en expresiones como: "hay polleros buenos, pero hay malos, y no sabes con quién te vas" (Antonia); "no puedes confiar, te trae el pollero; pero vienes con miedo" (Aurelia); "hay polleros buenos y malos" (Diana), o "hay polleros malos que secuestran a las personas" (Isabel). Sin embargo, en muchos casos el temor a ser violentadas por polleros malos contrastaba con su experiencia. Como decía Casilda: "hay polleros malos, pero los que me han traído son buenos". Blanca explicaba por qué los polleros tenían que tratar bien a los migrantes: "A ellos les conviene que hables bien de ellos porque así los recomiendas a más gente, porque ellos de eso la viven, de llevar gente; por eso te tratan bien, para que si luego vas los busques a que te lleven otra vez".

Como señala Spener (2009: p. 174), los coyotes necesitan acumular un capital simbólico; es decir, construir una buena reputación para ganarse la confianza de los migrantes, ya que estos los contratan a través de las recomendaciones de amigos o familiares. El negocio del tráfico de migrantes se sustenta en la recomendación de los clientes. Los polleros deben tratar bien a los migrantes para que su red sea recomendada a amigos, paisanos y familiares del migrante. Casi 
dos tercios de las entrevistadas tenían una opinión positiva de los polleros, y utilizaban calificativos que subrayaban la bondad y el buen trato recibido por parte de los polleros contratados (tabla 5).

Tabla 5. Opinión de las mujeres centroamericanas sobre los polleros

\begin{tabular}{|c|c|c|c|}
\hline & & $n$ & $\%$ \\
\hline \multirow{6}{*}{$\begin{array}{l}\text { Tenían una } \\
\text { opinión positiva } \\
\text { de los polleros }\end{array}$} & $\begin{array}{l}\text { Subrayaron la bondad de los polleros que contrataron. Los describieron como } \\
\text { buenos, buenas personas o personas de buenos sentimientos. }\end{array}$ & 38 & 47.5 \\
\hline & $\begin{array}{l}\text { Calificaron a los polleros como personas que las cuidaron de los peligros del } \\
\text { camino. }\end{array}$ & 16 & 20 \\
\hline & Refirieron el buen trato recibido por parte de los polleros. & 6 & 7.50 \\
\hline & Remarcaron el buen comportamiento de los polleros. & 7 & 8.75 \\
\hline & $\begin{array}{l}\text { Utilizaron adjetivos superlativos para subrayar su grado de satisfacción hacia } \\
\text { los polleros. }\end{array}$ & 5 & 6.25 \\
\hline & Total & 51 & 63.75 \\
\hline \multirow{4}{*}{$\begin{array}{l}\text { Tenían una } \\
\text { opinión negativa } \\
\text { de los polleros }\end{array}$} & $\begin{array}{l}\text { No utilizaron calificativos positivos ni negativos al hablar de los polleros que } \\
\text { contrataron; pero desconfiaban de ellos. }\end{array}$ & 7 & 8.75 \\
\hline & Utilizaron calificativos de carácter negativo para describir a los polleros. & 12 & 15 \\
\hline & $\begin{array}{l}\text { Afirmaron que los polleros que contrataron las trataron bien; pero tenían una } \\
\text { opinión negativa de ellos. }\end{array}$ & 10 & 12.5 \\
\hline & Total & 29 & 36.25 \\
\hline
\end{tabular}

Nota: El sumatorio es superior a 80 porque algunas entrevistadas utilizaron diferentes calificativos positivos para describir a los polleros.

Fuente: Elaboración propia.

En el discurso de las mujeres centroamericanas abundan las alusiones a la bondad, buen comportamiento y trato adecuado de los polleros que contrataron. Esto se refleja en expresiones como: "los polleros que me han ayudado han sido buenas personas" (Eusebia); "son buenas personas que hacen este trabajo llevando gente, y los acusan de traficantes de personas, pero son buenos" (Isabel); "han sido buenas personas, me ayudaron mucho" (Isidora); "eran unos buenos polleros; eran buenos, siempre me ayudaban" (Julia); "los polleros son buena onda" (Celsa); "han sido buenos, no me han tratado mal y me han cuidado" (Graciela); o "los polleros que me han ayudado han sido buenos, se han portado bien; la segunda vez que venía y traía a mi hija me la quisieron quitar y el pollero nos defendió” (Estela). Algunas de las entrevistadas utilizaban adjetivos superlativos como "el pollero era bien, a todo dar" (Pilar) o "para mi fueron a toda madre porque me ayudaron bien" (Laura) para expresar su elevado grado de satisfacción por el trato de los polleros. Como contraste, algo más de un tercio de las entrevistadas desconfiaban o tenían opiniones negativas de los polleros.

La experiencia de emigrar guiadas por un pollero no fue placentera para ninguna de las entrevistadas. Algunas viajaron escondidas en vehículos de doble fondo donde tenían dificultades para respirar, y todas sufrieron hambre, sed y mucho cansancio. Sin embargo, la mayor parte de las entrevistadas hablaban bien de los polleros, y estaban satisfechas de la forma como fueron tratadas. 
Esto corrobora la tesis de Spener (2009: p. 231) que afirma que migrantes y coyotes son copartícipes de una alianza estratégica contra un enemigo común. Las opiniones negativas de algunas mujeres pueden interpretarse, como señala Spener (2011: p. 172), en el contexto de la violencia estructural generada por las políticas de control fronterizo, que obliga a los coyotes a conducir a los migrantes por terrenos remotos o a protegerse a expensas de los segundos.

\section{Coyotaje y abuso sexual}

Los coyotes son descritos tanto en la prensa como en el discurso oficial como depredadores sexuales. Las autoridades también se han visto involucradas en agresiones sexuales. Sin embargo, mientras que entre los primeros tal conducta se considera normal, entre los últimos se ve como excepcional (Spener, 2011: p. 169). Como contraste, los datos de esta investigación indican que las mujeres centroamericanas en tránsito por México sufren mayor violencia sexual por parte de las autoridades que por parte de los polleros. Aunque en su mayoría las agresiones sexuales las comete la delincuencia organizada (tabla 6). ${ }^{4}$

Tabla 6. Mujeres que sufrieron algún tipo de agresión sexual durante su tránsito por México

\begin{tabular}{|c|c|c|c|c|}
\hline \multirow{13}{*}{$\begin{array}{l}\text { Migrantes centroa- } \\
\text { mericanas víctimas } \\
\text { de abuso sexual }\end{array}$} & Agresor & Descripción de la agresión & $n$ & $\%$ \\
\hline & \multirow{3}{*}{$\begin{array}{l}\text { Grupos } \\
\text { delictivos }\end{array}$} & Explotación sexual prolongada. & 27 & 33.75 \\
\hline & & Violación y robo antes de liberarlas. & 2 & 2.5 \\
\hline & & Total & 29 & 36.25 \\
\hline & \multirow{5}{*}{ Autoridades } & $\begin{array}{l}\text { Relaciones sexuales con agentes migratorios para evitar la } \\
\text { deportación. }\end{array}$ & 3 & 3.75 \\
\hline & & Violación y robo por parte de agentes migratorios. & 1 & 1.25 \\
\hline & & Abuso sexual por parte de agentes policiales. & 3 & 3.75 \\
\hline & & Violación y robo por parte de agentes policiales. & 1 & 1.25 \\
\hline & & Total & 8 & 10 \\
\hline & \multirow{3}{*}{ Pollero } & Pago con servicios sexuales. & 5 & 6.25 \\
\hline & & Abuso sexual por parte del pollero. & 2 & 2.5 \\
\hline & & Total & 7 & 8.75 \\
\hline & Total & & 44 & 55 \\
\hline \multicolumn{2}{|c|}{ No sufrieron abuso sexual } & & 36 & 45 \\
\hline
\end{tabular}

4 Las mujeres centroamericanas pagaron una tarifa para ser conducidas de modo subrepticio a otro país. Sin embargo, muchas fueron víctimas de trata. El tráfico de migrantes viola los derechos de los Estados, mientras que la trata de personas viola los derechos humanos. Las 27 mujeres que, en nuestra investigación, fueron secuestradas por los grupos delictivos y sufrieron explotación sexual prolongada en México, fueron víctimas de trata de personas, debido a que se les forzó a prostituirse. 
Más de la mitad de las mujeres entrevistadas sufrieron agresiones sexuales durante su tránsito por México; pero en solo siete casos los agresores fueron los polleros. Aunque, algunas mujeres afirmaron que accedieron a mantener relaciones sexuales con estos. Tres entrevistadas manifestaron que sedujeron a los polleros para obtener una mejor tarifa. Eran mayores de edad y dijeron que no fueron engañadas ni violentadas. Las entrevistadas afirmaban que ellas ejercían el control y no los polleros, que manipularon a estos porque no tenían dinero para pagar la tarifa que cobraban: "usé mis encantos y me pasó a México con mis hijos y mis hermanos, él me trajo de Guatemala a México, me dejó en Chiapas, y de ahí busqué quien me trajera a Chihuahua" (Begoña); "me fue bien, le pagué cien pesos por pasarme y dejarme en Chiapas, y me ocupé con él; tuve relaciones sexuales, y así no me cobró lo que era, me cobró menos (....) Yo le propuse pagarle así, yo sé cómo se hacen las cosas con los hombres, es cuestión de envolverlos y se consigue lo que se quiere, viniendo de Chiapas aquí, al D.F., me vine en un camión y al chófer le hice lo mismo, me acosté con él y me trajo" (Fausta).

La seducción y el enamoramiento son mecanismos que utilizan algunas mujeres para conseguir que los polleros las lleven a Estados Unidos cobrándoles un precio más económico. Lourdes, una mujer guatemalteca de treinta años de edad, llevaba varios meses viviendo en Reynosa (Tamaulipas) y deseaba ir a Estados Unidos lo antes posible. Pero, como no tenía dinero suficiente, había seducido a un pollero para que le cobrara una tarifa más reducida. Ella se refería a este pollero en los siguientes términos: "Me dijo que le pagara dos mil dólares y que me pasaba, me prometió llevarme con una seguridad muy buena, sin devolución; es un pollero que es bueno, me cobra poco porque está cobrando más; como está enamorado de mí, yo aprovecho eso para que me ayude".

Algunas de las entrevistadas que no sufrieron acoso sexual también señalaban que la prestación de favores sexuales constituía una moneda de cambio para obtener los servicios de los polleros: "yo había pagado; pero supe en ese momento que venía, que las que no pagaban en efectivo pagaban con cuerpo al coyote, u otros hombres que pagan por los servicios de las mujeres que venían" (María); "ellos no piden sexo porque uno les va pagando; si hay alguna que no paga con dinero, pues paga con su cuerpo" (Estela).

Este tipo de relaciones sexuales consensuadas no siempre son promovidas por las mujeres. Algunos polleros sacan provecho de una situación de vulnerabilidad para obtener gratificaciones sexuales. En algunos casos, mujeres mayores de edad acceden a la propuesta del pollero; pero lo hacen a disgusto, porque no encuentran otra forma de pagarles. Como decía Amalia: "lo que no me gustó fue que le pagara con cuerpo el favor que me hacía, si hubiera tenido dinero prefería pagar con dinero". En otros casos, mujeres menores de edad son manipuladas 
para que paguen con favores sexuales el costo de las tarifas. Gloria narraba que cuando llegó a los Estados Unidos, a la edad de 16 ańos, tuvo que mantener en múltiples ocasiones relaciones sexuales con el pollero. Ella decía: "no le pagué aquí, le pagué con trabajo y con favores estando allá (en Estados Unidos)”.

Sin embargo, el pago de la tarifa cobrada por los polleros no constituye una garantía de no sufrir acoso sexual. Dos de las mujeres entrevistadas, que habían pagado a los polleros, hablaban de su malestar durante el trayecto hacia los Estados Unidos debido al constante acoso sexual sufrido: "el que me cruzó de ahí para acá, sí era grosero, a mí me nalgueó varias veces, me agarró, solo eso, porque como venían más personas, y la mayoría eran hombres, por eso yo creo que no pasó a más; pero fue grosero" (Agustina); "le pagué al pollero para que me pasara, si no pago no me pasan; son bien cabrones, primero les pagas y si no traes dinero te piden otra cosa, te piden que te acuestes con ellos, o a veces hasta te agarran" (Clementina).

Otras entrevistadas narraban historias de abuso sexual por parte de los polleros; pero lo hacían en tercera persona. Decían que habían conocido a compañeras que habían sufrido agresiones sexuales. Por lo tanto, se consideraban afortunadas de haber contratado siempre a polleros buenos, que no abusaron de ellas: "la compañera platica que ella ya había viajado a Estados Unidos, y que a ella la habían agarrado, abusaron de ella en presencia de su esposo, y que fue ni más ni menos que el pollero que los llevaba a los dos" (Benedicta); “a mí, gracias a Dios que no me han hecho lo que les hacen a muchas de las mujeres centroamericanas que pasan a México, no a todas les pasa; pero algunas sí las llegan a violar, si no los polleros, los compañeros que vienen a México, al fin hombres, pues abusan de su poder" (Francisca); "me ha ido bien, al menos no me han abusado, pues a muchas de las mujeres que están aquí trabajando, y que son de allá, de Guatemala o Salvador, platican que los polleros abusan de ellas" (Gabriela).

Las redes simples unicelulares son consideradas por las mujeres centroamericanas como más seguras y fiables que las redes complejas pluricelulares. Sin embargo, la probabilidad de sufrir acoso sexual es más elevada en las primeras que en las últimas. En el primer tipo de redes los polleros son autónomos y no tienen que rendir cuentas a nadie. Por el contrario, los polleros que trabajan en redes complejas son asalariados que deben responder ante un líder. Los últimos no pueden transportar a las mujeres a cambio de favores sexuales porque ellos no cobran las tarifas. Asimismo, si abusan sexualmente de las mujeres, estas podrían quejarse y los polleros podrían perder su empleo. Además, el coyotaje es un negocio que busca generar ganancias económicas. Los polleros que ofrecen servicios gratuitos a las mujeres a cambio de favores sexuales incurren en pérdidas económicas. 
El abuso sexual no constituye la norma en el negocio del coyotaje. El objetivo de los polleros no es agredir a las mujeres, sino obtener una ganancia económica por la prestación de un servicio. El éxito profesional de estos depende de las recomendaciones de sus clientes. Si los últimos están satisfechos dirán a sus familiares y paisanos que contraten a un pollero o a una red de tráfico de migrantes específica. Por el contrario, si sufrieron algún tipo de abuso prevendrán a sus amigos, parientes y familiares para que no se fíen de esos polleros.

La mayor parte de las mujeres entrevistadas nunca fueron agredidas sexualmente por polleros. Pero casi todas tenían temor de sufrir agresiones sexuales por parte de ellos. En las conversaciones con otras amigas y paisanas, las entrevistadas escucharon relatos de mujeres agredidas. Por lo tanto, cuando explicaban cómo fue el comportamiento de los polleros que contrataron, en su mayor parte dejaban entrever que la conducta del pollero había sido mejor de lo que esperaban. Como decía Raquel: "no me pidieron nada a cambio, si me lo hubieran pedido no tenía otra opción, pero fueron respetuosos". Por lo tanto, al no ser agredidas, se consideraban afortunadas. Muchas de las entrevistadas deseaban encontrar un pollero que las tratase igual que la última vez que habían ido a Estados Unidos. Es el caso de Vicenta: "Ruego encontrarme un coyote como el que tuve para que me lleve al norte, porque fue bueno". Asimismo, en las entrevistas abundaban respuestas como: "fue amable, nos quedábamos a dormir en el tráiler y no abusó de mî" (Begoña); "no abusaba de nadie, yo era la más joven, la más chica, y no me faltó al respeto, ni me propuso nada que me hiciera sentir mal" (Daniela); "fueron muy respetuosos, siempre había límites y respetos hacia todas las personas del grupo" (Isidora); "no han abusado de mí; por lo contrario, me han ayudado" (Lourdes); "todos me trataban bien; no hablaban mal, ni me decían cosas malas, me trataron bien" (Mariana); "no abusaba de nadie, era un pollero muy profesional y dedicado a su trabajo" (Natalia), y "nadie de ellos, ni uno ni otro se comportaba mal, era lo contrario, cuidaban de mî" (Olga).

\section{Las mujeres engañadas por traficantes de migrantes}

Spener (2009: p. 155) habla de formas aberrantes de coyotaje, entre las que figura el falso coyotaje, o personas que se hacen pasar por coyotes pero que solo tienen la intención de robar a los migrantes; sin embargo, separa estas definiciones de coyotaje porque las considera poco comunes. En este sentido, una sexta parte de las mujeres entrevistadas no llegaron a Estados Unidos debido a que los polleros las engańaron o abandonaron (tabla 7). 
Tabla 7. Las mujeres abandonadas o engañadas por los polleros

\begin{tabular}{|c|c|c|c|}
\hline \multicolumn{2}{|r|}{ Circunstancia } & \multirow{2}{*}{$\begin{array}{l}n \\
7\end{array}$} & \multirow{2}{*}{$\begin{array}{c}\% \\
53.8\end{array}$} \\
\hline Fueron ahandonadas nor el nollero & $\begin{array}{l}\text { El pollero cobró la tarifa y alojó a las mujeres en un hotel; } \\
\text { pero nunca regresó, escapó con el dinero. }\end{array}$ & & \\
\hline $\begin{array}{l}\text { después de pagar la tarifa que les } \\
\text { pidió }\end{array}$ & $\begin{array}{l}\text { El pollero las condujo una parte del trayecto y las } \\
\text { abandonó. }\end{array}$ & 3 & 23.1 \\
\hline & Total & 10 & 76.9 \\
\hline \multicolumn{2}{|c|}{ Sospechan que el pollero que las conducía estuvo involucrado en el secuestro del grupo. } & 3 & 23.1 \\
\hline \multicolumn{2}{|c|}{ Contactaron al pollero por medio de una recomendación. } & 2 & 15.4 \\
\hline \multicolumn{2}{|c|}{ Contrataron a un pollero que nadie les recomendó. } & 11 & 84.6 \\
\hline \multicolumn{2}{|l|}{ Total } & 13 & 100 \\
\hline
\end{tabular}

Fuente: Elaboración propia.

Diez entrevistadas fueron abandonadas por el pollero luego de que este recibió el pago. En siete casos el pollero las abandonó en un hotel donde esperarían hasta que las recogiese, sin embargo, nunca llegó y escapó con el dinero. Asimismo, tres entrevistadas se sintieron engañadas porque el pollero las condujo durante una parte del trayecto, y después ya no quiso acompañarlas más.

Por otra parte, tres de las entrevistadas pensaban que el pollero que contrataron no solo se quedó con su dinero, sino que además las vendió a la delincuencia organizada, ya que la forma como su grupo fue abordado por los delincuentes pareció sospechosa.

Las mujeres abandonadas o engañadas no seleccionaron a los polleros con cuidado. Los migrantes no se fían de estos traficantes de migrantes porque saben que muchos solo engańan. Gran parte de los migrantes prefieren esperar semanas o meses hasta contratar a un pollero confiable que aceptar la invitación de un pollero del cual no tienen referencias. Otros tienen prisa por llegar a Estados Unidos y se arriesgan a contratar a un pollero desconocido en lugar de encontrar uno confiable. Otras veces los migrantes desean gastar poco dinero y se dejan embaucar por polleros que les ofrecen tarifas atractivas. Como decía Elena: "quise ahorrarme dinero y no gastar mucho para que me quedara”.

La mayor parte de las mujeres abandonadas o engañadas por los polleros, los contrataron sin ninguna referencia (tabla 7). En este sentido se expresa Elena: "nadie me lo recomendó, yo sola acepte venir con él, con ese pollero", u Honoria: "no conocía a nadie que me ayudara a escoger el pollero". Sin embargo, contratar a un pollero recomendado no siempre es una garantía. Dos de las mujeres entrevistadas fueron engañadas por polleros de los cuales tenían referencias positivas: "me lo recomendaron a mí por medio de una persona que conocía; pero me fue mal con él, nos robó a lo descarado y se quedó con el dinero que tenía" (Agustina); "este que me dejó aquí, me dijeron que era muy bueno, y no fue así, fue falso" (Dora). 
En otros casos las mujeres no llegaron hasta Estados Unidos debido a circunstancias que afectaron a los polleros. Dos de las entrevistadas relataron cómo los polleros que las conducían fueron asesinados por la delincuencia organizada; una escapó al ataque y otra fue secuestrada. Por otra parte, siete fueron deportadas cuando el pollero que las conducía fue detenido o escapó. En seis casos las autoridades migratorias interceptaron al grupo, de modo que ellas fueron deportadas y el pollero detenido; mientras que otra de las entrevistadas relató que el pollero huyó al percatarse de que su grupo iba a ser detenido por las autoridades (tabla 8).

Tabla 8. Mujeres que no llegaron a su destino por circunstancias que afectaron a los polleros

\begin{tabular}{lcc}
\hline & $n$ & $\%$ \\
\hline El pollero fue asesinado & 2 & 20 \\
El pollero fue detenido por las autoridades y las migrantes deportadas & 6 & 60 \\
El pollero escapó cuando su grupo fue interceptado por las autoridades migratorias mexicanas & 1 & 10 \\
Total & 10 & 100 \\
\hline Fuente: Elaboración
\end{tabular}

Fuente: Elaboración propia

La detención de traficantes de migrantes es entendida por las autoridades y por los medios de comunicación como un acto de defensa y protección de los derechos humanos de los migrantes. Sin embargo, estos no siempre lo ven así. Los migrantes contratan a los polleros para que estos los conduzcan a Estados Unidos, e invierten en ello todo su capital. Por lo tanto, cuando los polleros son detenidos y los migrantes son deportados, los últimos sufren una pérdida económica de la cual no pueden recuperarse. Para los migrantes la detención de los polleros no significa su rescate, sino su hundimiento en un abismo de deudas. Así, cuando son retornados a sus países vuelven a cruzar la frontera para hacer frente a este endeudamiento. Como lo señala Silvia:

La migra de México me deportó de Sonora; fuimos, según ellos, rescatados. Sí, íbamos al norte, nos detuvieron en el camino y deportaron al país de donde éramos, ya que iban distintas personas de diferentes lugares: de Guatemala, El Salvador, Nicaragua, Ecuador, Honduras. A todos nos deportaron estando en la frontera, fueron mierdas porque nos podían haber dejado allá que pasáramos, y no fue así, nos regresaron.

La autoridad considera a los migrantes como víctimas de los traficantes. Sin embargo, los primeros pocas veces denuncian a los últimos. En algunos casos esto puede deberse al temor a represalias; pero en otros obedece a una razón instrumental. La acción de denunciar al pollero no tiene ninguna utilidad para el migrante centroamericano que desea llegar a Estados Unidos; sin embargo, 
la acción de no denunciar sí que tiene una utilidad. En los dos escenarios el migrante es deportado hasta su país de origen. Pero en el primer caso el pollero es encarcelado y el migrante pierde el dinero que pagó; por el contrario, en el segundo, el migrante volverá a cruzar la frontera para buscar a ese mismo pollero que ya no le cobrará por conducirle al norte. Algunos migrantes no denuncian a los polleros debido a que se forjan lazos de amistad o paisanaje entre ambos; pero otros solo son pragmáticos. No obstante, los migrantes que deciden no denunciar a los polleros pasan de ser víctimas a cómplices, y deben soportar el acoso de las autoridades. Al respecto, Jimena decía: "Me deportaron a Guatemala desde el D.F.; ahí me deportaron, no me golpearon, pero sí insistían mucho para que les diera informes sobre el pollero que me había pasado. Como no les dije nada me llegaron a decir que era cómplice del pollero, porque lo encubría”.

\section{Conclusiones}

Las mujeres centroamericanas en tránsito por México son víctimas de abusos por parte de la delincuencia organizada, las autoridades y los traficantes de migrantes. Una sexta parte de las mujeres entrevistadas fueron engañadas y abandonadas por los polleros que las transportaban, y más de un tercio expresaban opiniones negativas de estos últimos. Como contraste, casi dos tercios de las entrevistadas hablaban positivamente de los polleros contratados.

Las entrevistadas sabían que había polleros que solo buscaban engañarlas y quedarse con su dinero; por lo tanto, no estaban dispuestas a contratar los servicios de cualquier persona. Algunas tenían dinero para continuar su viaje hasta Estados Unidos, pero en lugar de contratar a un pollero desconocido, llevaban semanas o meses esperando a uno confiable que les había sido recomendado por familiares, amigos o paisanos. Son pocas las mujeres que se aventuran a seguir a un pollero de quien no tienen ninguna referencia.

La opinión que tenían las mujeres de los traficantes de migrantes contrastaba con su valoración de la delincuencia organizada y de las autoridades. Ellas temen a los delincuentes porque les roban sus bienes, las secuestran y las explotan sexualmente. También temen a las autoridades. Algunas sufrieron robos y agresiones sexuales por parte de estas; aunque su mayor temor era la deportación. El discurso oficial presenta a las mujeres como víctimas de traficantes perversos, y la captura de estos se asume como la liberación de las mujeres que transportan. Sin embargo, para las mujeres la captura de sus guías significa su deportación y volver a iniciar un nuevo viaje, aunque ya sin recursos económicos. Las entrevistadas deportadas por las autoridades mexicanas a sus países, no regresaron a sus comunidades, volvieron a cruzar la frontera porque incurrieron en una deuda que únicamente 
podrán pagar trabajando en Estados Unidos. Si bien, emigrar sin dinero entraña demasiados riesgos. Muchas terminan trabajando en la prostitución para pagar la tarifa de los polleros; otras son víctimas de la delincuencia organizada. A modo de ejemplo, todas las entrevistadas que fueron deportadas de México a sus países de origen, cuando cruzaron nuevamente la frontera se convirtieron en objeto de explotación sexual prolongada por parte de los grupos delictivos.

En conclusión, las mujeres centroamericanas desconfían de los malos o falsos polleros que pululan en todo el territorio mexicano; pero dicen que muchos son buenos y por eso contratan sus servicios. Ellas ven a los polleros como sus aliados, porque generalmente las protegen de los delincuentes y evitan que las detengan las autoridades. Las mujeres recurren a los polleros para defenderse de un enemigo común: el Estado y la delincuencia organizada. Las mujeres indocumentadas y los polleros son perseguidos por los Estados porque vulneran la soberanía nacional al no utilizar los cauces legales para cruzar las fronteras. Ambos son víctimas de la delincuencia organizada, porque tanto las mujeres como los polleros sufren secuestros, extorsiones y asesinatos. Sin la ayuda de los polleros las mujeres centroamericanas serían más rápidamente interceptadas por las autoridades migratorias, encerradas y deportadas, y sin el apoyo de los primeros las últimas constituirían una presa más fácil para los grupos delictivos.

\section{Referencias}

Andrade Rubio, K.L. (2016). Víctimas de trata: mujeres migrantes, trabajo agrario y acoso sexual en Tamaulipas. CienciaUaT, 2(1), 22-36.

Cueva-Luna, T. E. \& Terrón-Caro, T. (2014). Vulnerabilidad de las mujeres migrantes en el cruce clandestino por Tamaulipas-Texas. Papeles de Población, 20(79), 209-241.

Izcara Palacios, S. P. (2015). Coyotaje and Drugs: Two Different Businesses. Bulletin of Latin American Research, 34(3), 324-339.

Izcara Palacios, S. P. (2014). La contracción de las redes de contrabando de migrantes en México. Revista de Estudios Sociales, (48), 84-99.

Izcara Palacios, S. P. (2012). El declive del contrabando de indocumentados en México. Mexican Studies, 28(2), 351-376.

López Castro, G. (1997). Coyotes and Alien Smuggling. En Binational Study: Migration between Mexico and the United States. Vol. 3 (pp. 965-974). Washington, D. C.: U.S. Commission on Immigration Reform. 
O'Leary, A. O. (2009). The abcs of migration costs: Assembling, bajadores and coyotes. Migration Letters, 6(1), 27-35.

Ramos, J. (2006). Dying to Cross. The Worst Immigrant Tragedy in American History. Nueva York: Harper.

Salt, J. \& Stein, J. (1997). Migration as a Business: The Case of Trafficking. International Migration, 35(4), 467-489.

Sánchez, G. (2015). Human Smuggling Facilitators in the US Southwest. En Pickering, S. \& Ham, J. (Eds.). The Routledge Handbook on Crime and International Migration (pp. 275-286). Nueva York: Routledge.

Slack, J. \& Whiteford, S. (2010). Viajes violentos: la transformación de la migración clandestina hacia Sonora y Arizona. Norteamérica, 5(2), 79-107.

Slack, J. (2015). Captives Bodies. Migrant Kidnapping and Deportation in Mexico. Area. doi: 10.1111/area.12151

Spener, D. (2011). Global Apartheid, Coyotaje, and the Discourse of Clandestine Migration. Distinctions between Personal, Structural, and Cultural Violence. En Kyle, D. \& Koslowski, R. (Eds.). Global Human Smuggling. Comparative Perspectives. Second Edition (pp. 157-185). Baltimore, Maryland: The Johns Hopkins University Press.

Spener, D. (2009). Clandestine Crossings: Migrants and Coyotes on the Texas-Mexico Border. Nueva York: Cornell University Press.

Terrón-Caro, T., Cueva, T. E., Cárdenas-Rodríguez, R. \& Vázquez, B. D. (2014). Riesgos, recursos socioeducativos y apoyo institucional para las mujeres migrantes en tránsito por Tamaulipas (México). Revista Española de Educación Comparada, (23), 135-159.

Triandafyllidou, A.\& Maroukis, T. (2012). Migrant Smuggling. Irregular Migration from Asia and Africa to Europe. Londres: Palgrave MacMillan.

Van Liempt, I. \& Sersli, S. (2013). State Responses and Migrant Experiences with Human Smuggling: A Reality Check. Antipode, (45), 1029-1046

Zhang, S. (2008). Chinese Human Smuggling Organizations. California: Stanford University Press.

Zhang, S. Chin, K.-L. \& Miller, J. (2007). Women's Participation in Chinese Transnational Human Smuggling: A Gendered Market Perspective. Criminology, 45(3), 699-732. 


\section{Anexo}

Entrevistas citadas en el texto. Los nombres son pseudónimos

\begin{tabular}{|c|c|}
\hline Nombre & Descripción de la entrevista \\
\hline Agustina & Realizada en agosto de 2011. Migrante guatemalteca de 30 años. \\
\hline Amalia & Realizada en septiembre de 2011. Migrante guatemalteca de 22 años. \\
\hline Antonia & Realizada en septiembre de 2012. Migrante guatemalteca de 38 años. \\
\hline Aurelia & Realizada en septiembre de 2012. Migrante guatemalteca de 29 años. \\
\hline Begoña & Realizada en septiembre de 2012. Migrante guatemalteca de 30 años. \\
\hline Benedicta & Realizada en septiembre de 2012. Migrante guatemalteca de 24 años. \\
\hline Blanca & Realizada en septiembre de 2012. Migrante guatemalteca de 30 años. \\
\hline Casilda & Realizada en noviembre de 2012. Migrante guatemalteca de 34 años. \\
\hline Celsa & Realizada en noviembre de 2012. Migrante salvadoreña de 31 años. \\
\hline Clementina & Realizada en enero de 2013. Migrante guatemalteca de 32 años. \\
\hline Daniela & Realizada en enero de 2013. Migrante guatemalteca de 24 años. \\
\hline Diana & Realizada en enero de 2013. Migrante guatemalteca de 28 años. \\
\hline Dora & Realizada en enero de 2013. Migrante guatemalteca de 25 años. \\
\hline Elena & Realizada en marzo de 2013. Migrante guatemalteca de 30 años. \\
\hline Estela & Realizada en marzo de 2013. Migrante guatemalteca de 32 años. \\
\hline Eusebia & Realizada en marzo de 2013. Migrante salvadoreña de 41 años. \\
\hline Fausta & Realizada en marzo de 2013. Migrante guatemalteca de 25 años. \\
\hline Florencia & Realizada en marzo de 2013. Migrante guatemalteca de 30 años. \\
\hline Francisca & Realizada en mayo de 2013. Migrante guatemalteca de 25 años. \\
\hline Gabriela & Realizada en julio de 2013. Migrante guatemalteca de 25 años. \\
\hline Gloria & Realizada en julio de 2013. Migrante guatemalteca de 32 años. \\
\hline Graciela & Realizada en julio de 2013. Migrante guatemalteca de 22 años. \\
\hline Honoria & Realizada en julio de 2013. Migrante hondureña de 22 años. \\
\hline Isabel & Realizada en julio de 2013. Migrante salvadoreña de 32 años. \\
\hline Isidora & Realizada en julio de 2013. Migrante hondureña de 28 años. \\
\hline Jimena & Realizada en diciembre de 2013. Migrante guatemalteca de 25 años. \\
\hline Julia & Realizada en diciembre de 2013. Migrante guatemalteca de 30 años. \\
\hline Laura & Realizada en diciembre de 2013. Migrante salvadoreña de 35 años. \\
\hline Lourdes & Realizada en diciembre de 2013. Migrante guatemalteca de 30 años. \\
\hline María & Realizada en abril de 2014. Migrante salvadoreña de 33 años. \\
\hline Mariana & Realizada en abril de 2014. Migrante guatemalteca de 21 años. \\
\hline Natalia & Realizada en abril de 2014. Migrante salvadoreña de 23 años. \\
\hline Norma & Realizada en abril de 2014. Migrante guatemalteca de 26 años. \\
\hline Olga & Realizada en abril de 2014. Migrante hondureña de 25 años. \\
\hline Pilar & Realizada en abril de 2014. Migrante salvadoreña de 25 años. \\
\hline Raquel & Realizada en julio de 2014. Migrante guatemalteca de 24 años. \\
\hline Silvia & Realizada en julio de 2014. Migrante salvadoreña de 28 años. \\
\hline Teresa & Realizada en julio de 2014. Migrante guatemalteca de 31 años. \\
\hline Vicenta & Realizada en julio de 2014. Migrante de Belice de 25 años. \\
\hline
\end{tabular}

\section{Recibido el 9 de marzo de 2015. Aceptado el 16 de junio de 2015.}

